\title{
Analisis Struktur dan Fungsi pada Satua I Sibakan
}

\author{
Dewa Gede Panca Diputra*, I Nyoman Duana Sutika, I Nyoman Darsana \\ Program Studi Sastra Bali, Fakultas Ilmu Budaya, Universitas Udayana \\ [dewapantja05.dp@gmail.com], [duana_sutika@yahoo.com], \\ [nym_darsana@unud.ac.id] \\ Denpasar, Bali, Indonesia \\ *Corresponding Author
}

\begin{abstract}
The study examines the satua text entitled I Sibakan with structure and function analysis. This research uses structural theory. The structural theory uses several opinions of literary experts, including: Sukada, Luxemburg, Teeuw, Esten, Nurgiyantoro, Tarigan, Sudjiman, Sukasa, Esten and Kridalaksana. The methods and techniques used in this study are divided into three stages, namely, 1) the stage of providing data using listening methods assisted with translation techniques and recording techniques, 2) the stage of data analysis using qualitative methods assisted by descriptive analysis techniques, 3) the stage of presentation of analysis results use informal methods assisted by using deductive-inductive techniques. After the structural stage is completed, it is continued to function in the use of function theory in Luxemburg's (1984: 94) opinion, stating that the function of a text is the overall traits that together lead to the same goals and their effects. A thing conveyed in a literary work still has to do with the real world that can be understood and accepted by the reader. The results obtained in the study are, the disclosure of the structure that builds each one in the satua I Sibakan text consisting of incidents, plot, character and characterization, setting, theme and mandate. In addition, this study also reveals the aspects of the functions contained in one group I Sibakan. Functions contained in satua I Sibakan include, the functions of religious life, the function of education, social functions, and functions as entertainment.
\end{abstract}

Keywords : satua, structure and value

\begin{abstract}
Abstrak
Penelitian ini mengkaji tentang teks satua yang berjudul I Sibakan dengan analisis struktur dan fungsi. Penelitian ini menggunakan teori struktural. Teori struktural tersebut menggunakan beberapa pendapat para ahli sastra, diantaranya: Sukada, Luxemburg, Teeuw, Esten, Nurgiyantoro, Tarigan, Sudjiman dan Kridalaksana. Metode dan teknik yang digunakan dalam penelitian ini dibagi menjadi tiga tahapan, yakni, 1) tahap penyediaan data menggunakan metode menyimak dibantu dengan teknik terjemahan dan
\end{abstract}


teknik pencatatan, 2) tahap analisis data menggunakan metode kualitatif dibantu dengan teknik deskipti fanalitik, 3) tahap penyajian hasil analisis menggunakan metode informal dibantu dengan menggunakan teknik deduktif-induktif. Setelah tahap struktur selesai dikaji, dilanjutkan pada tahap kajian fungsi yang menggunakan teori fungsi menurut pendapat Luxemburg (1984:94) menyebutkan bahwa fungsi sebuah teks adalah keseluruhan sifat-sifat yang bersama-sama menuju tujuan yang sama serta dampaknya. Suatu yang disampaikan dalam karya sastra tetap ada kaitannya dengan dunia nyata yang dapat dipahami dan diterima oleh pembaca. Hasil yang diperoleh dalam penelitian yakni, terungkapnya struktur yang membangun setiap satua dalam teks satua I Sibakan yang terdiri dari insiden, alur, tokoh dan penokohan, latar, tema dan amanat. Selain itu penelitian ini juga mengungkap aspek fungsi yang terdapat dalam satua $I$ Sibakan. Fungsi yang terkandung dalam satua I Sibakan diantaranya, fungsi kehidupan beragama, fungsi pendidikan, fungsi sosial, dan fungsi sebagai hiburan.

\section{Kata kunci : satua, struktur dan nilai}

\section{Latar Belakang}

Satua merupakan salah satu karya sastra dari kesusastraan Bali purwa (tradisional) yang banyak ditemukan dalam masyarakat Bali. Satua dalam kamus Bali-Indonesia adalah cerita dan mesatua berarti bercerita (Anom, dkk, 2008: 627). Tradisi masatua merupakan warisan kebudayaan yang telah ada sejak lama. Tradisi masatua di Bali memiliki berbagai fungsi, antara lain untuk hiburan dalam mengisi waktu senggang, menyampaikan berbagai nilai kehidupan lewat tokoh-tokoh dan dialog-dialognya termasuk pula pesan agama dan moral sesuai cara-cara tokohnya menyampaikan masalah tersebut (Suastika, 2011: 1-2). Salah satu satua yang menarik untuk diteliti adalah satua I Sibakan. Satua ini menarik untuk diteliti karena di dalamnya mengandung fungsi-fungsi yang dapat dijadikan cerminan dalam kehidupan. Satua I Sibakan, menceritakan tentang kehidupan seorang anak laki laki yang dilahirkan oleh seorang perempuan yatim piatu dan menikah dengan seorang lakilaki yang merupakan sepupunya sendiri. Namun seperti nama yang ia miliki "I Sibakan" yang berarti setengah/sebelah, anak ini memiliki bagian tubuh hanya setengah/sebelah. Namun hal tersebut tidak menyurutkan niat Sang Ibu untuk membesarkan anak tersebut dengan baik dan penuh kasih sayang. Dalam satua ini, anak laki-laki yang tidak memiliki bagian tubuh lengkap ini adalah anak yang lahir dari panugrahan Dewa yang menjelma sebagai kakek tua. Kakek tua tersebut memberikan setengah jajan laklak kepada ayah dari anak tersebut. ayahnya kemudian memberikan jajan itu kepada istrinya, dan membuat istrinya hamil. Ternyata anak tersebut lahir dengan berbadan sebelah, sehingga membuat ayahnya takut dan meninggalkan sang istri bersama anak yang memiliki badan sebelah itu. Anak laki-laki tersebut mencari cara agar memiliki tubuh yang utuh. Pada akhirnya ia bertemu dengan kakek tua jelmaan Bhatara Surya, yang memberikannya tubuh sempurna.

\section{Pokok Permasalahan}

a. Bagaimanakah struktur yang membangun teks satua I Sibakan?

b. Fungsi apa sajakah yang terkandung dalam satua I Sibakan? 


\section{Tujuan Penelitian}

Adapun tujuan dari penelitian ini adalah: 1) Untuk mendeskripsikan aspek struktur teks satua I Sibakan; 2) Untuk mengetahui fungsi yang terkandung dalam teks satua I Sibakan dalam hubungannya dengan masyarakat.

\section{Metode Penelitian}

Pada penelitian ini, metode dan teknik penelitian akan dibagi menjadi tiga tahapan, diantaranya:

a. Tahap Penyediaan Data

Metode yang digunakan ialah metode simak atau menyimak, selanjutnya dibantu dengan teknik transliterasi dan teknik terjemahan, dalam hal ini terjemahan dilakukan secara harfiah dan idiomatik (Larson, 1989:17).

b. Tahap Analisis Data

Dalam menganalisis data metode yang digunakan dalam penelitian ini adalah metode kualitatif. Metode ini nantinya dibantu dengan teknik deskriptif analitik yakni dengan cara mendeskripsikan fakta-fakta yang disusul dengan melakukan analisis atau menguraikan data (Ratna, 2004:53).

c. Tahap Penyajian Hasil Analisis Data Pada tahap ini, data yang telah dianalisis selanjutnya disajikan dengan metode informal. Metode ini ditunjang dengan teknik induktif dan deduktif (Sudaryanto, 1993:145).

\section{Hasil dan Pembahasan}

\subsection{Analisis Struktur Satua I Sibakan a. Insiden}

Insiden adalah kejadian-kejadian atau peristiwa-peristiwa yang terjadi di dalam sebuah cerita, tidak tergantung dari panjang atau pendeknya, yang secara menyeluruh membangun kerangka struktur cerita secara menyeluruh (Sukada, 1982:22). Berdasarkan hal tersebut maka terdapat beberapa insiden pada teks satua I Sibakan, meliputi: (1) Ketika I Lejat mencaci maki dan berkata kasar kepada para Dewa; (2) Ketika sang Dewa turun menjelma menjadi orang tua disaat I Lejat sedang mencaci-maki dan menghina para Dewa dan memberikan I Lejat setengah jajan laklak; (3) Ketika Ni Ubuh istri dari I Lejat hamil, setelah beberapa bulan kehamilan, anaknya pun lahir namun terlahir dengan bagian tubuh hanya setengah, membuat I Lejat merasakan takut dan pergi meninggalkan istri dan anaknya; (4) Ketika I Sibakan anak dari Ni Ubuh sudah tumbuh besar, dan ingin menikah dengan seorang wanita sehingga ia meminta ibunya untuk meminangkan seorang gadis; (5) Ketika I Sibakan menunjukan dimana saja ibunya harus pergi untuk melamar; (6) Ketika Men Sibakan melamar anak gadis yang rumahnya berada di ujung paling selatan; (7) Ketika Men Sibakan Sampai dirumanya, dan menceritakan semuanya kepada anaknya, saat itu pula I Sibakan mengobati ibunya; (8) Ketika Men Sibakan kembali datang untuk melamar anak gadis tetangganya yang rumahnya berada di tengah; (9) Ketika Men Sibakan sampai dirumah dan menceritakan perjalanannya melamar, saat itu pun I Sibakan mengobati ibunya; (10) Ketika Men Sibakan kembali pergi untuk melamar anak gadis yang rumahnya berada di ujung paling utara, respon keluarga sang gadis sangat beda dengan keluarga sebelumnya, dan mau menerima lamaran Men Sibakan tetapi dengan syarat I Sibakan harus memiliki bagian tubuh yang utuh; (11) Ketika I Sibakan mendengar berita tersebut, dan meminta ibunya untuk membuatkan dia bekal untuk pergi bersemedi di hutan; (12) Ketika I Sibakan sudah bersemedi di hutan selama tujuh hari, saat itu turunlah Dewa yang memberikan ayahnya dulu setengah jajan laklak ,mengabulkan permintaan I Sibakan yang ingin 
memiliki bagian tubuh utuh seperti manusia normal lainnya; (13) Ketika sang Dewa memberikan sebuah wahyu agar I Sibakan dapat memiliki apa yang dia inginkaan; (14) Ketika I Sibakan sampai dirumahnya dan menceritakan semua hal bagaimana ia bisa berbadan utuh, saat itu pula I Sibakan mengujudkan semua keinginannya; (15) Ketika kedua tetangganya yang menolak untuk menikah dengan I Sibakan menghina tetangganya yang mau menerima lamaran I Sibakan, mereka menghina dan menjelek-jelekkan tetangganya; (16) Ketika perjalanan I Sibakan menjemput calon istrinya, dengan menaiki kuda dan diiringi suara gambelan; (17) Ketika warga desa semuanya heran akan ketampanan I Sibakan, semua warga bertanya-tanya bagaimana bisa, I Sibakan memiliki tubuh yang utuh dan kekayaan. Kedua gadis yang menolakpun, menyesal setelah melihat semuanya.

\section{b. Alur}

Alur cerita teks Satua I Sibakan yakni diawali dengan tahap penyituasian (situation) yakni pada bagian ini pengarang memaparkan mengenai keadaan tokoh $\mathrm{Ni}$ Ubuh dan I Lejat; selanjutnya tahap pemunculan konflik (generating circumstances) yaitu menceritakan saat $\mathrm{Ni}$ Ubuh belum memiliki seorang anak, dan menyinggung perasaan I Lejat; berikutnya tahap peningkatan konflik (rising action) yakni menceritakan tentang perjalanan Men Sibakan meminangkan seorang gadis untuk sibakan; selanjutnya tahap klimaks (climax) yaitu saat I Sibakan bertapa di tengah hutan, dan datanglah Dewa yang membantunya memiliki tubuh yang utuh; dan terakhir tahap penyelesaian (denouement) yakni saat I Sibakan pergi untuk melamar sang gadis, yang bersedia menerima I Sibakan bila sudah memiliki tubuh yang utuh.

c. Tokoh dan Penokohan

1. Tokoh Utama : I Sibakan menggambarkan perwatakan tokoh utama dengan dimensi struktur Fisiologis, Sosiologis, dan Psikologis yang khas membedakan tokoh utama dengan tokoh lainnya

2. Tokoh Sekunder : Ni Ubuh, I Lejat, dan Kakek Tua,

3. Tokoh Komplementer : Tetangganya di Banjar Kajanan yang rumahnya di ujung selatan, tengah dan utara

d. Latar

1. Latar Waktu : pada saat beberapa bulan kehamilan $\mathrm{Ni}$ Ubuh hingga ia melahirkan; pada pagi hari saat I Sibakan pergi bertapa ke hutan

2. Latar Tempat : di Banjar Kanginan; di Pura Puseh; di Banjar Kajanan; di rumah pertama (Banjar Kajanan); di rumah tengah (Banjar Kajanan); di rumah ujung paling utara; di hutan

3. Latar Suasana : suasana emosi, takut, mencekam, bahagia, dan terheranheran

\section{e. Tema}

Tema dalam teks satua I Sibakan adalah tentang "Karmaphala" karena saat I Lejat berkata-kata kasar kepada Dewa, turunlah Dewa yang menyamar sebagai kakek tua yang memberikan I Lejat setengah jajan laklak dan diberikan kepada istrinya agar memiliki seorang anak, kemudian lahirlah anaknya dengan memiliki bagian tubuh hanya setengah yang diberi nama I Sibakan.

\section{f. Amanat}

Pada intinya pesan-pesan yang terkandung dalam teks satia I Sibakan adalah ajakan atau seruan untuk melaksakan dan mengamalkan beberapa ajaran pokok mengenai kewajiban 
seseorang dalam ajaran Panca Sradha khususnya yang berkaitan dengan karmaphala.

\subsection{Analisis Fungsi Satua I Sibakan}

a. Fungsi Religuis

Dalam teks satua I Sibakan, kepercayaan bertapa atau bersemedi dipercayai sebagai hal yang dapat mengabulkan keinginan seseorang jika hal tersebut dilakukan dengan bersungguh-sungguh, seperti halnya I Sibakan yang diberikan badan yang utuh oleh Dewa karena ia bersungguhsungguh dengan tekatnya.

\section{b. Fungsi Pendidikan}

Tercermin dalam keadaan I Sibakan yang terlahir dengan keadaan tubuh hanya setengah karena sifat ayahnya terdahulu. Hal tersebut mencerminkan bahwa prilaku baik akan memperoleh hal yang baik, begitu pula perilaku yang buruk akan memperoleh hasil yang buruk pula namun ia memiliki seorang ibu yang rela berkorban merawat anaknya dengan keadaan fisik tidak normal. Melalui tokoh I Lejat diharapkan mampu menyadari serta membentuk karakter anak dan remaja dalam berprilaku dan berkata yang di lingkungannya, sebab hasil dari perbuatannya tidak hanya dinikmati oleh dirinya sendiri, namun pada anaknya juga.

\section{c. Fungsi Sosial}

Digambarkan dengan sikap I Sibakan yang mementingkan keegoisan sehingga tanpa berpikir akan keselamatan Ibunya saat melamar gadis yang dimintanya. Sebagai anak harus tetap menghormati orang tua yang telah melahirkan dan memberikan pendidikan kepada kita.

\section{d. Fungsi Hiburan}

Karya sastra teks satia I Sibakan berfungsi sebagai media penghibur karena dapat disampaikan dalam dua hal, yaitu sebagai pertunjukan dan dipentaskan karena berisi tokoh yang dapat dijadikan panutan oleh masyarakat dan juga sebagai naskah atau teks yang dibaca oleh masyarakat sehingga wawasan menjadi terbuka dan setelah selesai membaca seseorang bisa menjadi lebih senang sehingga mendapat beberapa nilai-nilai serta amanat di dalam karya sastra tersebut.

\section{Simpulan}

Berdasarkan pada uraian diatas, maka dapat disimpulkan sebagai berikut:

Struktur naratif teks satua I Sibakan terdiri atas tujuh belas insiden; Alur yang digunakan dalam teks satua I Sibakan menggunakan alur lurus sorot balik (flashback); Penokohan dalam teks satua I Sibakan terdiri dari delapan tokoh, I Sibakan sebagai tokoh utama, kemudian tokoh sekunder yaitu I Lejat, Ni Ubuh, Kakek Tua, dan Ida Bhatara, serta tokoh komplementer, yakni tetangganya di selatan, tengah, dan utara. Dianalisis melalui dimensi strusktur fisiologis, sosiologis dan, psikologis secara analitik, dramatik, dan gabungan; Latar yang terdapat dalam teks satua I Sibakan adalah latar waktu (pagi hari dan beberapa bulan), latar tempat (di Banjar Kanginan, Pura puseh, Banjar Kajanan, rumah ujung paling selatan di Banjar Kajanan, rumah di tengah di Banjar Kajanan, rumah ujung paling utara di Banjar Kajanan, dan di hutan), dan latar suasana (emosi, mencekam, bahagia, dan terheran-heran); Tema dari teks satua I Sibakan adalah karmaphala (buah atau hasil dari perbuatan); Amanat dalam teks satua I Sibakan yaitu ajakan atau seruan untuk melaksanakan dan mengamalkan beberapa ajaran pokok mengenai kewajiban seseorang dalam ajaran Panca Sradha khususnya yang berkaitan dengan karmaphala.

Fungsi yang terkandung dalam teks satua I Sibakan meliputi fungsi sebagai 
kehidupan religius, fungsi sebagai alat pendidikan anak dan remaja, fungsi sosial yang meliputi sikap bakti dan hormat atau susila, fungsi sebagai media hiburan.

\section{Saran}

Teks satua I Sibakan merupakan karya sastra Bali tradisional mengandung nilai-nilai yang dapat dijadikan pedoman dalam masyarakat. Berdasarkan hal tersebut para penikmat karya sastra diharapkan untuk senantiasa menggali kembali mengenai apa yang terkandung dalam karya sastra, di dalam karya ini tidak hanya berhenti sebatas ini.

\section{Daftar Pustaka}

Anom, dkk. 2008. Kamus Bali-Indonesia Berdasarkan Latin dan Bali. Denpasar: Kerjasama Dinas Kebudayaan Kota Denpasar dengan Badan Pembina Bahasa, Aksara, dan Sastra Bali Provinsi Bali

Larson, Milfred. 1989. Penerjemahan Berdasar Makna Pedoman Untuk Pemandanan Antar Bahasa. Jakarta: Arcan

Luxemburg, Jan Van. 1984. Pengantar Ilmu Sastra Jakarta: PT. Gramedia.

Ratna, Nyoman Kutha, 2004. Teori, Metode, dan teknik Penelitian Sastra. Yogyakarta: Pustaka Larasan

Suastika, I Made. 2011. Tradisi Sastra Lisan (Satua) di Bali. Denpasar: Pustaka Larasan

Sudaryanto, 1993. Metode dan Aneka Teknik Analisis Bahasa. Yogyakarta: Duta Wacana University Press
Sukada, I Made. 1982. Masalah sistemasi Cipta Sastra. Lembaga Pendidikan Dokumentasi dan Publikasi Fakultas Sastra Universitas Udayana 